\section{Contribution of Change Management for Continuous Improvement of Public Hospital: The Case of Adama Hospital Medical Collage, Adama, Ethiopia}

\section{Abstract}

Background: Deficiencies in continuous improvement of health care organizations caused by neither the failure of professional compassion nor necessarily a lack of resources. Rather, results from gaps in knowledge, readiness for change, sustaining change, inappropriate applications of available technology, or the inability of organizations to change.

Objectives: The central purpose of this study is to examine the contribution of change management for continues improvement within Adam Hospital Medical Collage.

Methods: Descriptive cross-sectional research design was applied. The total number of target population is 226 , out of this 180 respondents was sampled through probability sampling method. The questionnaire consisting of both open and close ended questions was used to collect data's. Descriptive and inferential statistics was used to analyze the data. Descriptive statistics that were used in the study are mean and standard deviation. Inferential statics used was Pearson correlation and multiple regression analysis to find out the contribution of change management for continuous improvement.

Results: The findings confirm that there is a significant correlation between change readiness, sustaining change, change resistance and continuous improvement of Adam Hospital Medical Collage. More specifically this research confirms the findings of earlier work and reveals the same pattern of correlations between the variables. In addition the findings suggest that there is also a significant impact of change management (readiness, sustaining \& resistance) on continuous improvement of Adam Hospital Medical Collage.

Conclusion: To sum up, all findings clearly depicts that change readiness, sustaining change and continuous improvement were low and resistance to change was high in the organization.

Keywords: Change management; Resistance to change; Change readiness; Continues improvement

\section{Alemu ST ${ }^{1 *}$, Teka $\mathrm{YD}^{2}$, Kitila KT르, Gebretsadik DM ${ }^{2}$ and Shiberu NNB ${ }^{1}$}

\section{Department of Management, Arsi University School of Business and Economics, Arsi, Ethiopia \\ 2 Ethiopia Public Health Institute, Addis Ababa, Ethiopia}

\section{*Corresponding author: Alemu ST \\ Đsamibonny11@gmail.com}

Department of Management, Arsi University School of Business and Economics, Arsi, Ethiopia.

Tel: +251912150505

Citation: Alemu ST, Teka YD, Kitila KT, Gebretsadik DM, Shiberu NNB (2018) Contribution of Change Management for Continuous Improvement of Public Hospital: The Case of Adama Hospital Medical Collage, Adama, Ethiopia. J Hosp Med Manage Vol.4 No.2:8

Received: October 05, 2018; Accepted: October 25, 2018; Published: October 30, 2018

\section{Abbreviations}

BPR: Business Process Reengineering; BSC: Balanced Score Card; Cl: Continuous Improvement; CPD: Continues Professional Développent; CR: Change Readiness; EFMOH: Ethiopian Federal
Ministry of Health; FMHACA: Food, Medicine and Healthcare Administration and Control Authority; NHS: National Health Society; MDG: Mellinium Goal Development; SC: Sustaining Change; TQM: Total Quality Management; RC: Resistance to Change; QI: Quality Improvement. 


\section{Introduction}

\section{Background of the study}

Change is the only dynamic process in today's life - for individuals and organizations. Some changes can be reversible while others are not hence the risk involved in managing change. According to Smith [1] change can be due to technological changes, demographical changes and situational changes. Balogun and Hailey [2] argue that all organizations are currently undergoing some type of change. Many of these change programs arise from management fads such as culture change, business process engineering, empowerment and total quality.

Improvement in the quality of hospital care in a continues base is a fundamental aspect of health system strengthening that is directly linked to the service delivery dimension of the World Health Organization (WHO) building blocks of a health system. While the monitoring of hospital performance is a key ingredient to such improvement many countries struggle to develop and implement feasible strategies to monitor hospitals nationally McCannon et al. [3]. The challenge is particularly acute in low-income countries where resources for measurement and reporting are scarce.

Cultivating an environment conducive to change entails gaining commitment and overcoming resistance. This can be accomplished by understanding the motives of those affected by the change and determining whether they view the change positively or negatively. In order to secure commitment to change, an individual must perceive the positive factors associated with change as outweighing the negative. In the context of healthcare, building commitment entails gaining the support of the entire system, from patients to doctors, to front-line nurses and hospital administrators, to personal support workers and governmental officials. The presence of strong leadership and the ability to establish new forms of cooperation will play an important role in cultural transformation. Change must be undertaken with the patients' interests at the center (Lamb MC and MA Cox 2000) [4].

Doherty and Horne (2002) [5] elaborated on why some public sector employees resist change. They asserted that a large number of public sector organizations continue to operate in a 'mechanical' manner performing their roles in a structured fashion resulting in greater resistance to change. They argued that public sector employees find it difficult to convey decisions to management despite the devolution of the decision-making process. Furthermore, they stated that public sector employees tend to resist change because some managers exaggerate the outcomes of the changes they have initiated.

Quality Improvement (QI) is a proven, effective way to improve care for patients, residents and clients, and to improve practice for staff. In the healthcare system, there are always opportunities to optimize, streamline, develop and test processes, and QI should be a continuous process and an integral part of everyone's work, regardless of role or position within the organization. International evidence suggests that improving the quality of obstetric care on a continuous base can directly reduce maternal and neonatal deaths. Accurate and reliable data are needed on the quality of services provided at health facilities in Ethiopia, especially for complicated deliveries involving postpartum hemorrhage, preeclampsia/eclampsia, and newborn asphyxia (Health Quality Ontario, 2012) [6].

Health service quality is the key component of the health sector development plan IV and the Ethiopian Health reform implementation guideline addressed quality management as one chapter of the reform implementation. As part of this national effort, the reform in the health sector has been intensified through the application of a new concept known as Business Process Reengineering (BPR). In addition a process itself forms a fundamental rethinking and requires a purposeful and radical redesign of health business processes to achieve dramatic improvements in critical, contemporary measures of performance such as cost, quality, service and speed (FMOH, 2010) [7].

Delivering high quality health service by health facilities is achieved through the implementation of continuous quality improvement. Quality improvement is now a driving force in health care and is an essential aspect of service delivery at all levels Ashebir et al. [8]. Good health management systems are crucial for addressing health challenges and improving health service delivery on a continuous base in developing countries. Thus the study focuses on assessment of change management contribution for continuous improvement of public Hospital.

The Ethiopian public sector organizations had been trying to implement various modern management systems and tools since 1995 such as, "Result-oriented Performance Evaluation Method", Business Process Reengineering (BPR), Balanced Scorecard (BSC) and kaizen in order to improve efficiency (Adebabay, 2011) [9]. Federal Ministry of Health of Ethiopia has developed the continuous improvement guideline and hospital performance monitoring and improvement manual of Ethiopia. Many lowand middle-income countries have developed ambitious health policies and strategies to improve health service delivery (HSD) and attain the health-related Millennium Development Goals, but have difficulty in matching implementation with their aspirations (Sameh El-Saharty, 2009) [10].

Deficiencies in continues improvement of quality of health care represent neither the failure of professional compassion nor necessarily a lack of resources. Rather, they result from gaps in knowledge, readiness for change, sustaining change, inappropriate applications of available technology, or the inability of organizations to change. Local health care systems may have failed to align practitioner change readiness, sustaining change and resistance to change in order to measure clinical practice, or to link continues health care improvement to better health outcomes John W. Peabody et al. [11].

Hence, this study was contributed in examining the contribution of change readiness, sustaining change, change resistance on continuous improvement of the public Hospital in the case of Adama Hospital Medical Collage. 


\section{Methods and Materials}

\section{Research design and setting}

To achieve the aforementioned objectives, Cross-sectional study designed was employed through descriptive and exploratory design in which both quantitative and qualitative data was used to produce richer and more complete information to meet the intended goal. It had included the collection of data both from primary and secondary sources [12].

\section{Study and target population}

The target population of the study was employees of Adama Hospital Medical Collage.

\section{Sampling technique}

A probability sampling technique was used to sample the respondents. In this method of sampling, each unit included in the sample has certain pre assigned chance of inclusion in the sample. This sampling provides the better estimate of parameters in the studies in comparison to purposive sampling. For the purpose of this study simple random sampling technique was used. In Simple random sampling method, each unit included in the sample has equal chance of inclusion in the sample. This technique provides the unbiased and better estimate of the parameters Masuku et al. [13].

\section{Sample size determination}

The following formula is used by the researcher to determine the sample size for a given population. A representative sample size with known confidence level which is $95 \%$ was selected, based on the formula of Yamane 1967 [14].

Therefore considering the above given points the sample size for this study is calculated as follows (Zikmund, 2010).

$\mathrm{n}=\frac{\mathrm{N}}{1+\mathrm{N}(\mathrm{e})^{2}}$

Where:

$\mathbf{n}=$ the sample size/ required sample size

$\mathbf{N}=$ the population size

$\mathbf{1}=$ designates the probability of the event occurring

$\mathbf{e}=$ the level of precision (Sampling error that can be tolerated which is $5 \%$ ).

Assumptions: A $\mathbf{9 5 \%}$ confidence level, and $\mathbf{e}=\mathbf{\pm} \mathbf{5 \%}$

Therefore:

$$
\mathrm{n}=\frac{520}{1+520(0.05) 2} \quad \mathrm{n}=\underline{\mathbf{2 2 6}}
$$

So, a total of 226 respondents (around $40 \%$ of the total population) were selected to gather relevant data to complete the research work.

\section{Data Collection Instrument}

The researcher used questionnaire as instruments of data collection. The questionnaire consists of both open and close ended questions was designed and distributed to the employee to examine contribution of change management for continuous improvement of Adama Hospital Medical Collage.

\section{Data Analysis}

In this study there was a number of statistical tests were used to analyze the results of this study. First, frequencies, means, and standard deviations were used to describe the sample (demographics) and general results. Pearson correlations were used to test magnitude and direction of the relationship for all four variables. Although correlations also provided some data into construct relationships (and significant differences) with variables, the primary method of analysis was a multiple regression analyses of variance. This was useful in determining the relationships between each of the constructs (change readiness, sustaining change, résistance and continuous improvement).

Descriptive analysis is the basic transformation of raw data in a manner that describe the basic characteristics of data that helps the researcher to comprehend, reorganize and manipulate the data into information that can be easily described (Zikmund, Babin, Carr \& Griffin 2010). The collected data was checked for completeness, edited, transcribed and coded. Data from questionnaire was transferred to computer to statistical package for social science (SPSS 20.0) for analysis.

\section{Results and Discussions}

According Hertzog MA (2008), around 10\% $(n=25)$ of the sample size was used to calculate over all crobach's alpha and it was found that 0.968 which shows higher degree of internal consistence. The individual crombachs alpha test of the variables was described in the following Table 1.

The questionnaires for the study were distributed to employees of Adama Hospital Medical. A total of $(\mathrm{N}=226)$ questionnaires were distributed to the respondents and out of these questionnaires a total of $(n=180)$ questionnaires were successfully completed and returned. Although there is no agreed standard of a minimum response rate Fowler (2002) suggests that a common minimum should be in the region of $75 \%$. The total response rate was nearly $80 \%$. As a result, the analysis of this research is based on the number of questionnaires collected.

\section{Demographic Information}

The researcher collected demographic information on

Table 1: Crobach's alpha test of the variables.

\begin{tabular}{|c|c|c|}
\hline Variables & Cronbach's Alpha & No of items \\
\hline Change readiness & 0.962 & 19 \\
\hline Sustaining change & 0.943 & 12 \\
\hline Resistance to change & 0.913 & 8 \\
\hline Continuous improvement & 0.916 & 14 \\
\hline
\end{tabular}


respondents" gender, age, education level, work experience, education level, job title \& length of service in the Hospital. The sample characteristics of 226 respondents from Adama Hospital Medical Collage were analyzed. The findings are presented in Table 2.

Findings in Table $\mathbf{2}$ indicate that majority of the respondents were male (73.3\%). Female respondents were (26.7\%). This shows that females were at least one third of the respondents.

As far as age of respondents is concerned (43.3\%) of the respondents are in the range of $20-29$ years; $(35.0 \%)$ of the respondents are in the range of $30-39$ years; $(15.0 \%)$ are in the range of $40-49$ years, (5\%) are in the range of $50-59$ and $(1.7 \%)$ are above 60 years. This shows that the majority of the employees in Adama Hospital Medical Collage rein the range of 20-29 years; therefore, the majority of employees are within the productive age.

With regard to educational level of respondents, second degree and above holders of the respondent represented (9\%) of the sample; Master's Degree holders represented (15\%) of the sample; First Degree holders represented (65\%) of the sample. The college diploma holders constitute $(20 \%)$ of the sample; and $(1.7 \%)$ of the respondents have certificate. It can be said from the survey that, most of the Adama Hospital Medical collage employees were degree holders. The lowest numbers of respondents were certificate holder.

With regard to service years of respondents in the Adama Hospital Medical Collage, $(53.3 \%)$ of the respondents have less than 5 years of experience. (21.7\%) respondents have 6-10 years' experience, $(25 \%)$ have above 10 year experience.

\section{Regarding Change Management and Continuous Improvement of Participants}

The descriptive statistics was used as a way to examine the mean, standard deviation and other information which are not apparent in the raw data. It was needed to determine the employees' perception about change management (readiness, sustaining and resistance) and continuous improvement practices in their organizations. Tables 3-7 below contains descriptive data (mean and standard deviations) for the subscale of contribution of change management for continuous improvement of Adama Hospital Medical Collage, as indicated by the respondents. In all cases, the distribution of scores for the sample contained reasonable variance and normality for use in subsequent analyses.

The above Table 3 shows the mean and standard deviation of Adama Hospital Medical Collage change readiness construct. The findings indicate that the mean and standard deviation value for each of the change readiness scales were calculated between $(\mathrm{M}=2.33$ to 3.48$)$ and $(\mathrm{SD}=.861$ to 1.286$)$ respectively. The highest standard deviation value indicates that a wide spread of responses. The finding in this study shows low level of change readiness and it was different from the study done by Susan
R. Madsen (2005) in lasvagas Overall, employees in that study perceived themselves as generally open and ready for change with a statistical mean $(M=5.27)$ on a 7-point scale of strongly disagree (1) to strongly agree (7).

Finding in Table 4, shows the mean and standard deviation for Adama Hospital Medical Collage sustaining change subscale. The study finding indicate that the mean and standard deviation value for each of the sustaining change scales were calculated between $(\mathrm{M}=2.20$ to 2.82$)$ and $(\mathrm{SD}=.93$ to 1.51$)$ respectively; which indicates that low level of sustaining change in the organization.

The finding in Table $\mathbf{5}$ above shows the mean and standard deviation for Adama Hospital Medical Collage change resistance subscale. The finding of the study indicates that the mean and standard deviation value for each of the change resistance scales were calculated between $(M=2.18$ to 2.72$)$ and $(S D=1.027$ to $1.347)$ respectively on a 5 -point scale of strongly disagree (1) to strongly agree (5); which indicates that high level of resistance to change in the organization. Lower mean score is interpreted as higher level of resistance in the organization with the resistance to change subscale.

A finding in Table 6 shows the mean and standard deviation for Adam Hospital Medical Collage continuous improvement subscale. Findings indicate that the mean and standard deviation value for each of the change resistance subscales were calculated between ( $M=2.35$ to 3.02$)$ and $(S D=.942$ to 1.412$)$ respectively; which shows the low level of the organization continuous improvement.

According to Tryggvi Hallgrímsson [15] change readiness scores for the organizations $(M=3.76 ; S D=0.85)$ which indicates high level of change readiness. The cumulative mean score obtained

Table 2: Demographic statistics gender, age, profession, educational level and Length of experience of Adama Hospital medical Collage, 2017.

\begin{tabular}{|c|c|c|c|}
\hline \multirow{2}{*}{ Characteristics } & \multicolumn{3}{|c|}{ Respondents profile } \\
\hline & Variables & Frequency & percent \\
\hline \multirow{2}{*}{ Sex } & Male & 132 & 73.3 \\
\hline & Female & 48 & 26.7 \\
\hline \multirow{5}{*}{ Age } & $20-29$ year old & 78 & 43.3 \\
\hline & 30-39 year old & 63 & 35.0 \\
\hline & $40-49$ years old & 27 & 15.0 \\
\hline & $50-59$ years old & 9 & 5.0 \\
\hline & 60 year or old & 3 & 1.7 \\
\hline \multirow{5}{*}{ Professions } & Medical doctor & 90 & 50.0 \\
\hline & pharmacist & 15 & 8.3 \\
\hline & Nurse & 30 & 16.7 \\
\hline & Health officer & 18 & 10.0 \\
\hline & Others & 27 & 15.0 \\
\hline \multirow{3}{*}{$\begin{array}{l}\text { Length of } \\
\text { Experience }\end{array}$} & Less than 5 Years & 96 & 53.3 \\
\hline & 6-10 Years & 39 & 21.7 \\
\hline & Above 10 years & 45 & 25.0 \\
\hline \multirow{5}{*}{ Education Level } & Certificate & 3 & 1.7 \\
\hline & Diploma & 36 & 20.0 \\
\hline & First degree & 117 & 65.0 \\
\hline & Second degree & 15 & 8.3 \\
\hline & Above & 9 & 5.0 \\
\hline
\end{tabular}


Table 3: Demographic statistics gender, age, profession, educational level and Length of experience of Adama Hospital medical Collage, 2017.

\begin{tabular}{|c|c|c|c|}
\hline Variable (change readiness) & $\mathrm{n}$ & Mean & Std. Dev \\
\hline The organization has a clearly defined vision, mission and strategy. & 180 & 3.48 & 1.2210 \\
\hline Priorities are set and continually communicated regarding change projects. & 180 & 2.880 & 1.0850 \\
\hline The organization uses multiple communication methods to keep stakeholders informed. & 180 & 2.900 & 1.210 \\
\hline The organization's direction about change projects is clear, concise and consistent. & 180 & 2.820 & 1.106 \\
\hline Change initiatives within the organization have an identified executive sponsor. & 180 & 2.630 & 1.128 \\
\hline $\begin{array}{l}\text { The executive sponsor has the necessary authority over the people, processes and systems to authorize and } \\
\text { fund change initiatives. }\end{array}$ & 180 & 2.720 & .8610 \\
\hline The executive sponsor can build awareness of the need for change (why the change is happening). & 180 & 2.820 & 1.136 \\
\hline $\begin{array}{l}\text { The executive sponsor will actively and visibly participate with the project team throughout the entire change } \\
\text { process. }\end{array}$ & 180 & 2.770 & 1.089 \\
\hline $\begin{array}{c}\text { The executive sponsor will resolve issues and make decisions relating to the change project schedule, scope and } \\
\text { resources. }\end{array}$ & 180 & 2.550 & 1.1050 \\
\hline Stakeholders hear a consistent and unified message from various levels of executives. & 180 & 2.520 & 1.0270 \\
\hline Change initiatives are accurately tailored to the particular needs and concerns of each stakeholder group. & 180 & 2.550 & 1.0580 \\
\hline Special tactics have been developed for handling opposition to change from various stakeholders. & 180 & 2.520 & 1.0110 \\
\hline $\begin{array}{c}\text { Change management team members have been identified. Managers and staff are trained on Organizational } \\
\text { Change Management. }\end{array}$ & 180 & 2.420 & 1.103 \\
\hline $\begin{array}{l}\text { Change management teams are tracking progress and able to resolve related issues through set project } \\
\text { management processes. }\end{array}$ & 180 & 2.630 & 1.214 \\
\hline Resources for change projects are identified and acquired based on a project plan. & 180 & 2.570 & 1.286 \\
\hline Feedback processes are continually used to determine how effectively change is being adopted by stakeholders. & 180 & 2.330 & 1.210 \\
\hline Organization recognizes and reinforces skills and behaviors required for the change effort. & 180 & 2.520 & 1.151 \\
\hline Skills and knowledge needed for transition have been identified. & 180 & 2.520 & 1.207 \\
\hline Skills assessments are continually conducted for change projects and gaps are identified for transition. & 180 & 2.43 & 1.073 \\
\hline
\end{tabular}

Table 4: Mean and Standard Deviations of organizational sustaining change of Adama Hospital medical Collage, 2017.

\begin{tabular}{|c|c|c|c|}
\hline Variable(Sustaining change) & $\mathbf{n}$ & Mean & Std. Dev \\
\hline Organizational change had leadership support. & 180 & 2.750 & 1.167 \\
\hline Organizational change had strong public support. & 180 & 2.820 & 1.510 \\
\hline The change process has funded continuously. & 180 & 2.470 & 1.043 \\
\hline Community leaders are involved with the change. & 180 & 2.620 & 1.085 \\
\hline The community was engaged in the development of change goals. & 180 & 2.650 & 1.049 \\
\hline The change was well integrated into the operations of the organization. & 180 & 2.570 \\
\hline Organizational systems have been directed to support the various change needs. & 180 & 2.670 & 1.119 \\
\hline Leadership was efficiently managed staff and other resources. & 180 & 2.200 \\
\hline The change had adequate staff to complete the change goals. & 180 & 2.550 & 1.930 \\
\hline The change makes decisions about which components are ineffective and should not continue. & 180 & 2.680 \\
\hline The change provides evidence to the public that the change works. & 180 & 2.580 \\
\hline The change demonstrates its value to the public. & 180 & 2.270 & 1.073 \\
\hline
\end{tabular}

Table 5: Mean and Standard Deviations of organizational change resistance of Adama Hospital medical Collage, 2017.

\begin{tabular}{|c|c|c|c|}
\hline Variable(Resistance to change) & $\mathbf{n}$ & Mean & Std. Dev. \\
\hline Organization members were excited to be part of the change. & 180 & 2.72 & 1.347 \\
\hline There was a great opportunities for the organization members in the change. & 180 & 2.37 \\
\hline Organization members supported the implementation of the change. & 180 & 2.72 \\
\hline Organizations members were benefited from the change. & 180 & 2.38 & 1.143 \\
\hline Organizations member's uncertainties have been addressed. & 180 & 2.33 & 1.256 \\
\hline Organizations members were grown because of the change. & 180 & 2.180 \\
\hline Organizations members had necessary knowledge to cope with the change. & 180 & 2.70 & 1.027 \\
\hline A structured change management approach is being communicated and applied to change projects. & 180 & 2.40 \\
\hline
\end{tabular}

in this study for change readiness was lower than Tryggvi Hallgrímsson (2008). The finding of the cumulative mean score $(M=2.66 ; S D=0.86)$ in this study indicates that the level of change readiness in Adam Hospital Medical College is low.
Study on resistance in Spanish company, Starting with the means, it is observable that the lowest mean is 1.65 and the highest 2.70 Pardo del Val [16], so resistance to change exists but it is generally not too strong to affect the change process seriously, 
Table 6: Mean \&St. Deviations of organizational continuous improvement of Adama Hospital medical Collage, 2017.

\begin{tabular}{|c|c|c|c|}
\hline Variable (change readiness) & $\mathbf{n}$ & Mean & Std. Dev. \\
\hline Our organization has set a strategic plan where continuous improvement objectives are accomplished. & 180 & 2.82 & 1.060 \\
\hline Our organization continuous improvement goals are aligned to fulfill the organization overall objectives. & 180 & 2.62 & 1.069 \\
\hline $\begin{array}{l}\text { Our organization has a systematic process where continuous improvement goals are continuously revised and } \\
\text { adjusted. }\end{array}$ & 180 & 2.43 & .975 \\
\hline Our organization "true north" is to continuously improve to meet our internal and external customers' needs. & 180 & 2.52 & 1.248 \\
\hline There was strong commitment to continuous improvement practices in all functional units of our organization. & 180 & 2.48 & 1.075 \\
\hline $\begin{array}{l}\text { Continuous improvement implementation brought quality services in terms of efficiency, effectiveness and } \\
\text { transparency in our organization. }\end{array}$ & 180 & 2.50 & 1.151 \\
\hline Our organization has an effective and quick continuous improvement goals review. & 180 & 2.38 & 1.069 \\
\hline $\begin{array}{c}\text { Our organization has set the required resources across the organization to support the continuous improvement } \\
\text { process. }\end{array}$ & 180 & 2.47 & .942 \\
\hline Performance of continuous improvement goals was frequently monitored in our organization & 180 & 2.35 & 1.000 \\
\hline There is an established system for training and education in our organization. & 180 & 2.45 & 1.178 \\
\hline $\begin{array}{l}\text { Lack of proper incentives are challenges for } \\
\text { implementation } \\
\text { Of continuous improvement of our organization. }\end{array}$ & 180 & 3.02 & 1.412 \\
\hline $\begin{array}{l}\text { The continuous improvement technique of our organization increased employees/team members interest in the } \\
\text { work area. }\end{array}$ & 180 & 2.35 & 1.111 \\
\hline Employees/ teams gained new skills as a result of continuous improvement of our organization. & 180 & 2.50 & 1.060 \\
\hline Continuous improvement has been creating organizational culture and values for change in our organization. & 180 & 2.52 & .960 \\
\hline
\end{tabular}

Table 7: Summary of Cumulative Descriptive Statistics of Adama Hospital medical Collage, 2017.

\begin{tabular}{|c|c|c|c|}
\hline Variables & $\mathbf{n}$ & Mean & Std. Dev. \\
\hline Change Readiness & 180 & 2.6614 & .86522 \\
\hline Sustaining Change & 180 & 2.5681 & .84377 \\
\hline Change Resistance & 180 & 2.4750 & .91336 \\
\hline Continuous Improvement & 180 & 2.5286 & .78423 \\
\hline
\end{tabular}

considering that the scale allowed scores up to 5 lowest mean score indicates high level of resistance. According to the finding of this study in Adam Hospital Medical Collage cumulative mean $(M=2.475 ; S D=0.91)$ which indicates high level of resistance to change in the organization.

The cumulative mean $(M=2.568 ; S D=0.843)$ for sustaining change and $(M=2.528 ; S D=0.784)$ continuous improvement subscales also indicates that low level of sustaining change and continuous improvement in the organization.

\section{Relationship between Change Management and Continuous Improvement}

The objective of this study was examining the contribution of change management on continuous improvement at Adam Hospital Medical Collage. In this section, correlation analysis conducted in the light of each research questions is mentioned. The relationship between change management and continuous improvement was investigated using one-tailed Pearson correlation analysis. This provided correlation coefficients which indicated the strength and direction of relationship. The $p$-value also indicated the probability of this relationship's significance.

According to Huck [17], a positive correlation coefficient ( $r$ ) indicates a positive and direct relationship and a negative correlation coefficient $(r)$ indicates a negative relationship and an indirect or inverse relationship between the two variables (change management and continuous improvement) Table 7. A zero correlation indicates that there is no correlation between the variables. The value of correlation coefficients $(r)$ nearer to +1 or -1 indicates high degree of correlation between the two variables.

According to Somwkh and Lewin [18], if correlation coefficient ( $r$ ) is below 0.33 it is considered to be a weak relationship; if correlation coefficient $(r)$ is between 0.34 and 0.66 it indicates a medium strength relationship; and if correlation coefficient $(r)$ is between 0.67 and 0.99 it indicates a strong relationship. The significance of relationship was determined by $p$-value. For this study significance level of 0.05 or 0.01 were taken as the standard for a one-tailed test of correlation. These findings are presented below.

Table 8 presents correlation analysis which was computed from the mean average of each independent and dependent constructs. The correlation analysis with significance level is the requirement to perform regression analysis. It is important to see the significance level of the coefficients of the correlation between the independent constructs, Change Readiness, Sustaining Change, Change Resistance and Continuous Improvement. Pearson's correlation test was used to measure the degree of significance between the study variables.

The Table 8 shows that the value of Pearson's correlation coefficient between every pair of variables. We can see that 
all independent variables have large positive correlation with Continuous Improvement. The following are the correlation results for every constructs. Change Readiness $r(180)=.695$, $p<.001$, Sustaining Change $r(180)=.786, p<.001$, and Change Resistance $r(180)=.729, p<.001$. The correlation of each independent constructs is significant at 0.01 levels (1-tailed). The number of cases contributing to each correlation $(n=180)$ is shown. The result of the significance level shows it is possible to perform the regression analysis to know the effect of each constructs on Continuous Improvement.

Finding in this study shows that there is a strong positive correlation $r(180)=0.695, p<0.001$ between change Readiness and Continuous Improvement at Adam Hospital Medical Collage. These finding is supported by the study of Somatunga LC et al. [19]; where change readiness correlation with the continuous quality Program implementation was $r=0.387$, it was statistically significant which indicates medium strength of relationship between change readiness and continuous quality improvement. As well as strong positive correlation was found between sustaining change and Continuous Improvement $r(180)=0.786$, $p<0.001$ and change resistance and Continuous Improvement $r$ $(180)=0.729, p<0.001$.

\section{Contribution of Change Management for Continuous Improvement}

Multiple regression analysis was employed to examine the effect of change management (change readiness, sustaining change and change resistance) on continuous Improvement. Regression tests the deviation about the means, and all variables must be at least interval scaled. Multiple regression analysis is chosen as it helps to predict the linear relationship of a dependent variable and one or more independent variables.
The regression analysis was run to show the contribution of Change Readiness, Sustaining Change, and Change Resistance for Continuous Improvement. Tables which are relevant with the study objectives are presented in Table 9.

\section{The impact of change readiness on continuous improvement}

In line with objective one; that is to determine the impact of change readiness on continuous improvement of Adama Hospital Medical Collage, the beta value (standardized coefficient of regression) of change readiness has a positive and significant effect on continuous improvement of Adama Hospital Medical Collage with a $\beta=.233, p<.001$. This implies that, if change readiness increases by 1 percent, continuous improvement will increase by .233 . This interpretation is true only if the effects of sustaining change and change resistance are held constant. Therefore, the finding in this study indicate that, change readiness has a positive and significant effect on continuous improvement of Adam Hospital Medical Collage. The finding of this study was supported by by Anees Janee Ali et al. [20], where the results of the regression analysis showed that strategic focus (change readiness) had a significant impact on sustainability of $\mathrm{Cl}$ capabilities in an organization. This was proven through the significance value of 0.000 and beta coefficient of 0.299 (Table 10).

\section{The impact of sustaining change on continuous improvement}

In line with objective two; that is to examine the impact of Sustaining change on continuous improvement of Adama Hospital Medical Collage, the beta value(standardized coefficient

Table 8: Pearson Correlation between Change Management (readiness, sustaining \& resistance) and Continuous Improvement of Adam Hospital Medical Collage, Adama, Ethiopia, 2017.

\begin{tabular}{|c|c|c|c|c|c|}
\hline & & CR & SC & RC & Cl \\
\hline \multirow{2}{*}{ Change Readiness } & Pearson Correlation & 1 & & & \\
\hline & Sig. (1-tailed) & & & & \\
\hline \multirow{2}{*}{ Sustaining Change } & Pearson Correlation & $.759^{* *}$ & 1 & & \\
\hline & Sig. (1-tailed) & .000 & & & \\
\hline \multirow{2}{*}{ Change Resistance } & Pearson Correlation & $.587^{* *}$ & $.777^{* *}$ & 1 & \\
\hline & Sig.(1-tailed) & .000 & .000 & & \\
\hline \multirow{2}{*}{$\begin{array}{l}\text { Continuous } \\
\text { Improvement }\end{array}$} & Pearson Correlation & $.695^{* *}$ & $.786^{* *}$ & $.729^{* *}$ & 1 \\
\hline & Sig. (1-tailed) & .000 & .000 & .000 & \\
\hline
\end{tabular}

Table 9: Regression analysis result of Change Management (Readiness's, Sustaining and Resistance) with Continuous Improvement of Adama Hospital medical Collage, 2017.

\begin{tabular}{|c|c|c|c|c|c|c|}
\hline \multirow{2}{*}{\multicolumn{2}{|c|}{ Model }} & \multicolumn{2}{|c|}{ Unstandardized Coefficients } & \multirow{2}{*}{$\begin{array}{c}\text { Standardized Coefficients } \\
\text { Beta }\end{array}$} & \multirow{2}{*}{$\mathbf{t}$} & \multirow{2}{*}{ Sig. } \\
\hline & & B & Std. Error & & & \\
\hline \multirow{4}{*}{1} & (Constant) & .430 & .116 & & 3.700 & .000 \\
\hline & Change readiness & .212 & .060 & .233 & 3.549 & .000 \\
\hline & Sustaining change & .351 & .079 & .378 & 4.471 & .000 \\
\hline & Change resistance & .256 & .058 & .298 & 4.384 & .000 \\
\hline
\end{tabular}


Table 10: Summary of Research Objective Results of Adama Hospital medical Collage, 2017.

\section{Research Objectives}

Change readiness has impact on continuous improvement.

Change sustaining has impact on continuous improvement.

Change resistance has impact on continuous improvement.

Change management has aggregate impact on continuous improvement.
Objective Result/Relation

significant

significant

significant

significant of regression) of Sustaining Change has a positive and significant effect on continuous improvement of Adam Hospital Medical Collage with a $\beta=.378, p<.001$. This implies that, if sustaining change increases by 1 percent, continuous improvement will increase by .378. This interpretation is true only if the effects of change readiness and change resistance are held constant.

Therefore, the researcher inferred that, sustaining change has a positive and significant effect on continuous improvement of Adam Hospital Medical Collage. This finding was supported by the study of Anees Janee Ali et al. [20]; the results of the regression analysis showed that management of Continuous Improvement had a significant impact on sustainability of capabilities in an organization. This was proven through the significance value of 0.000 and beta coefficient of 0.244 .

\section{The impact of resistance to change on continuous improvement}

In line with our objective three; that is to determine the impact of Resistance to change on continuous improvement of Adama Hospital Medical Collage, the beta value (standardized coefficient of regression) of Resistance to Change has a positive and significant effect on continuous improvement of Adam Hospital Medical Collage with a $\beta=.298, p<.001$. This implies that, if change resistance that arises in the organization managed by 1 percent, continuous improvement will increase by 298. This interpretation is true only if the effects of change readiness and sustaining change are held constant. Therefore, the researcher inferred that, if change resistance managed properly has a positive and significant effect on continuous improvement of Adam Hospital Medical Collage.

\section{Aggregate effect of change management on continuous improvement}

In line with objective four, the aggregate Effect of Change Management on Continuous Improvement. With 95\% confidence interval the aggregate effect is significant. In the column labeled sum of squares which is a measure of how much of the variability in the outcome is accounted for the whole predictors. The result of sum of squares indicate that the aggregate effect of all independent variables such as change readiness, sustaining change and change resistance accounted for $67.7 \%$ of the contribution to continuous improvement of Adam Hospital Medical Collage with $\mathrm{R}^{2}=.677, F(1,180)=122.77, p<.01$. Thus, $67.7 \%$ of the variation in continuous improvement can be explained by the change readiness, sustaining change and change resistance. Other unexplored variables or factors may limit the contribution of change management for continuous improvement of Adam Hospital Medical Collage by accounting for about $32.3 \%$.

\section{Summary and Recommendation}

Overall, this study found that there was a significant contribution of change management for continuous improvement in Adama Hospital Medical Collage. In this organization, as examined, change readiness, sustaining change and continuous improvement was low. The resistance to change found was high. The research findings suggest that statistically significant positive correlations exist between three change management variables, namely, change readiness, sustaining change, and resistance to change; and continuous improvement. This study also found that there was a strong impact of change readiness, sustaining change and resistance to change on continuous improvement. These findings were typically in line with previous research.

\section{Conclusion}

In line to our objective, the result of the study found that significant positive impact of change readiness, sustaining change and high significant impact of resistance to change on continuous improvement. This implies that, if change resistance that arises in the organization managed properly, it has significant impact on continuous improvement.

In line with another our objectives, the result of sum of squares indicate that the aggregate effect of all independent variables such as change readiness, sustaining change and change resistance accounted for $67.7 \%$ of the contribution to continuous improvement of Adam Hospital Medical Collage $\left(R^{2}=.677\right)$. Thus, $67.7 \%$ of the variation in continuous improvement can be explained by the change readiness, sustaining change and change resistance.

As a recommendations based on the findings presented in this study, the researcher found the following implications for practice.

$\diamond \quad$ Leaders better to have a clear understanding of necessary steps to succeed and must be educated in motivating and preparing employees for change. Preferably, this should be done on continuous bases.

$\diamond \quad$ The organization better to confirm the change readiness of the employees before implementing change management tools. This may be done through trainings and resource allocation for the projects focused on the change readiness of the employees.

$\diamond \quad$ Leaders better to address resistance before implementing change management tools and resistance need to be handled properly in order to continuously improve the service of the organization. 
$\diamond \quad$ The organization better to develop intervention strategy for sustaining organizational change in order to improve the quality of the service.

\section{Implication for Further Research}

The study found out that change management (readiness, sustaining \& resistance) significantly contributed for the continuous improvement. The study also found out that employee noninvolvement in the change process, poor working conditions, employee resistance, poor Executive sponsorship, and lack of awareness are some of the challenges facing change management at Adam Hospital Medical Collage.

As employees' resistance has positive as well as negative effects on organizational continuous improvement, further work can be done to find out the factors that creates/increase the positive effects of employees' resistance. Since, this study found that resistance to change was positively related to continuous improvement if properly managed.

It is therefore recommended that a similar research be replicated in other public Hospitals in seeking to implement a change management tools properly in order to insure sustainable continuous improvement of Ethiopian Public Hospital. The results should then be shared so as to ensure whether there are consistencies on the challenges they encounter when they implement change management tools.

This study had been significant as its results contribute to the knowledge base essential for the practice of Hospital administrators and management by explaining the interactive effects of factors that affect change and how to use this to their knowledge. The findings and recommendations of this study provide valuable information to Practicing Hospital management especially how they would be able to obtain information about how different change management affects the effective continuous improvement. The results are also important to the Ministry of Health and its partners, it is hoped that the results adduced from the study may serve to inform decision making and policy development on change management and overall management of health facilities of Ethiopia. The study is also important to the academicians in building their knowledge base and creating an insight in understanding overall management functions with regard to change management.

\section{Limitation of the Study}

In under taking this study some limitations were encountered. The following were the major factors that had contributed to the limitation of the study: lack of secondary data related to change management tools since they are a recent phenomenon to the country and lack of well-documented records or absence of keeping records. The result of the study were also had a limitation, as the result of case study cannot be generalized to other situations except the case under investigation.

As a result the study was limited to examine contribution of change management for continues improvement of Adama Hospital Medical College. However, other Public Hospital out of Adama town was not assessed/included on this study.

\section{Data Availability}

Data used to support the findings of this study cannot be shared in a publicly available data repository system, because there is no such a data repository system in the country. However, the data are available from the authors upon request.

\section{Ethical Approval}

Study was conducted after it was ethically reviewed and approved by the Institutional Review Board (IRB) of Arsi University School of Business and Economics department of Management. Ethical clearance was also obtained from Addis Ababa Health Bureau. Then, a letter informing the hospital was written from the health bureau, and permission was obtained from the Hospital.

\section{Consent}

Informed written consents were obtained from the study participants before data collection. The respondent was given the right to refuse to take part in the study as well as to withdraw at any time during the study period. All the information obtained from the study subjects was coded to maintain confidentially.

\section{Conflicts of Interest}

The authors declare that they have no conflicts of interest.

\section{Authors' Contributions}

ST conceived and designed the study protocol, collected data, performed analysis, and interpreted data. KT, YD, DM and BS critically reviewed and made progressive suggestions from the design to final write up of the result. All of the authors participated in data collection, analysis, interpretation, critically evaluated and approved the manuscript.

\section{Acknowledgment}

The authors would like to acknowledge Arsi University, School of Business and Economics Department of Management for creating and facilitating this research work opportunity. The authors express their heartfelt thanks to the study participants of staff members of the hospitals for their willingness and being involved in this study.

\section{References}

1. Smith DK (1996) Taking Charge of Change: 10 Principles For Managing People and Performance, Massachusetts: Addison-Wesley Publishing Company.

2. Balogun J, Hailey VH (2008) Exploring Strategic Change. 3rd Edition, Prentice Education Limited England.

3. McCannon CJ, Berwick DM, Massoud MR (2007) The science of largescale change in Global health. JAMA 298: 1937-9. 
4. Lamb MC, Cox MA (1999) Implementing change in the National Health Service. J Manag Med 13: 288-298.

5. Doherty T, Horne T (2002) Managing public services: Implementing changes. London, UK: Routledge.

6. Health Quality Ontario (HQO) (2012) Quality Improvement Guide.

7. Medical Service Directorate (2010), Ethiopian Federal Ministry of Health. Quality Improvement: Reference Manual for Facility Managers and Health Service Providers.

8. Ashebir G, Ricca J, Cantor D, Rawlins B, Rosen H et al. (2011) Quality of Care for Prevention and Management of Common Maternal and Newborn Complications: A Study of Ethiopia's Hospitals.

9. Adebabay A (2011) Promoting and Strengthening Professionalism in the Civil Service. Independent Assessment of the implementation of the BSC in Ethiopia, Addis Ababa, Ethiopia.

10. El-Saharty S, Kebede S, Dubusho PO, Siadat B (2009) Ethiopia Improving Health Service Delivery.

11. Peabody JW, Taguiwalo MM, Robalino DA, Frenk J (2005) Improving the Quality of Care in Developing Countries. J Change Manag 5: 391-406.

12. Zikmund WG, Babin BJ, Carr JC, Griffin M (2010) Business research method (8th ed.).
13. Masuku, Micah B (2014) Sampling techniques and determinants of sample size in applied statistics research. Inter J Econ, Commer and Manag 2: 1-22.

14. Taro Y (1967) Applied statistics an introductory analysis, 2nd edition, New York: Harper and Row.

15. Hallgrímsson $T$ (2008) Organizational change and change readiness: Employees' attitudes during times of proposed merger. Norway, pp: 60-64.

16. Del Val P (2000) Resistance to change empirical finding in best fifty Spanish company that that undergoes change process. pp: 8-14.

17. Huck (2012) Reading Statistics and Research, 6th Edition, University of Tennessee, p: 312.

18. Somwkh, Lewin (2005) Research method in social science; University of California, p: 267.

19. Somatunga LC, Sridharan S, Refai MACM, Malavige KK, Gamini LPS (2015) Factors Influencing Continuous Quality Improvement Programme in Government Hospitals of Sri Lanka. Inter J Sci Technol Res 4: 4-6.

20. Ali AJ, Aminul M, Howe LP (2010) Critical Factors Impacting Sustainability of continuous Improvement in manufacturing Industries in Malaysia. World J Manag 2: 65-80. 